6-ARTIGO ORIGINAL

\title{
Comparação entre pericárdio bovino preservado em glicerina e malha de poliéster no reparo de falhas da parede abdominal em ratos ${ }^{1}$
}

\author{
Juliany Gomes Quitzan² \\ Sheila Canevese Rahal ${ }^{3}$ \\ Noeme Souza Rocha ${ }^{4}$ \\ Adalberto José Crocci ${ }^{5}$
}

Quitzan GQ, Rahal SC, Rocha NS, Crocci, AJ. Comparação entre pericárdio bovino preservado em
glicerina e malha de poliéster no reparo de falhas da parede abdominal em ratos. Acta Cir Bras
[serial online] 2003 Jul-Ago;18(4). Disponível em URL: http://www.scielo.br/acb.

RESUMO - Objetivo: Comparar uma malha comercial de poliéster com o pericárdio bovino preservado em glicerina na reconstituição de defeitos da parede abdominal. Métodos: Foram utilizados 30 ratos, divididos em dois grupos eqüitativos. Efetuou-se uma excisão retangular de $2,5 \times 2 \mathrm{~cm}$, incluindo toda a musculatura abdominal e peritônio. No grupo I a parede abdominal foi reparada com malha de poliéster e no grupo II com pericárdio bovino conservado em glicerina. Os animais foram sacrificados aos 15, 60 e 90 dias de pós-operatório, sendo o local cirúrgico avaliado macroscópica e histologicamente. Resultados: Os animais do grupo I apresentaram aderências mais severas e em maior número quando comparados aos do grupo II; porém, sem comprometimento funcional. A análise histológica revelou incorporação dos tecidos aos implantes, com maior resposta fibroblástica nos animais do grupo I. Conclusão: A malha de poliéster oferece maior resistência estrutural e resposta fibroblástica mais intensa; contudo, promove grande quantidade de aderências às vísceras abdominais, quando comparada ao pericárdio bovino.

DESCRITORES - Parede abdominal. Malha. Poliéster. Pericárdio. Ratos.

\section{Introdução}

Várias membranas biológicas e implantes sintéticos têm sido pesquisados com o objetivo de reparar alterações anatômicas ou adquiridas e, dentre estas, as falhas na parede abdominal ${ }^{1,2}$. A principal finalidade destes materiais é fornecer um arcabouço para o desenvolvimento de um novo tecido, restabelecendo as estruturas afetadas $^{3}$. Entre as membranas biológicas destaca-se o emprego do pericárdio homólogo ou heterólogo conservado em glicerina ${ }^{4}$ ou glutaraldeído ${ }^{1}$.
A glicerina atua desidratando o tecido e removendo a maior parte da água intracelular, sem contudo alterar as concentrações iônicas das células, sendo por isso eficaz fixador e protetor da integridade celular. Aumenta a resistência à tração e não altera a elasticidade. Age ainda como poderoso anti-séptico, exceto contra as formas esporuladas. A ausência de reações inflamatórias agudas dos implantes indica a baixa antigenicidade do transplante obtido por este meio de conservação, somado ao baixo custo e facilidade de manuseio do produto ${ }^{5}$.

1. Trabalho realizado no Departamento de Cirurgia e Anestesiologia Veterinária da Faculdade de Medicina Veterinária e Zootecnia (FMVZ) - UNESP, Botucatu - SP.

2. Residente (R2) na área de Cirurgia de Pequenos Animais - FMVZ - Unesp, Botucatu - SP.

3. Docente, Departamento de Cirurgia e Anestesiologia Veterinária - FMVZ - Unesp, Botucatu - SP.

4. Docente, Departamento de Clínica Veterinária - FMVZ, Unesp - Botucatu.

5. Docente, Departamento de Bioestatística - IB - Unesp, Botucatu - SP. 
Santillán-Doherty et al. (1995) ${ }^{1}$ avaliaram a resistência in vitro da bioprótese de pericárdio, preservada em diferentes concentrações de glutaraldeído. A concentração de $0,5 \%$ conferiu resistência adequada em relação a concentrações maiores e malhas comerciais de polipropileno (Marlex) e poliéster (Mersilene). Também foi estudada a capacidade da prótese de glutaraldeído a $0,5 \%$ no reparo de defeito induzido experimentalmente na parede abdominal, torácica, diafragma e esterno de cães. Na cavidade torácica quase não ocorreram aderências e na parede abdominal estas foram de grau acentuado junto ao omento. No entanto, não afetaram o funcionamento de nenhum órgão. Também em nenhum caso houve reação tipo corpo estranho e infecção. A histopatologia mostrou uma reação inflamatória mínima a moderada com presença de algumas células gigantes e proliferação de vasos neoformados. Ocorreu formação de uma camada de fibroblastos sobre a prótese com depósito de colágeno e integração da prótese ao defeito.

Entre as malhas sintéticas que são freqüentemente utilizadas para o reparo de defeitos da parede tóracoabdominal estão as de náilon e poliéster (Mersilene), polipropileno (Marlex), poliuretano (Gore-Tex), cada uma tendo suas vantagens e desvantagens ${ }^{1,6,7}$.

Wantz $(1991)^{2}$ reparou, com uma prótese de Mersilene (fibra de poliéster), trinta hérnias incisionais em humanos, no espaço entre os músculos abdominais e peritônio. A prótese preveniu eventração peritoneal por aderir ao saco visceral tornando-o não distensível, além de unir e consolidar a parede abdominal. Afirmou ser a prótese suficientemente flexível e elástica para adaptar-se às curvaturas do saco visceral, com a necessária textura para prender-se ao peritônio e suficientemente reativa para induzir rápida resposta fibroblástica, assegurando a fixação.

Pans e Pierard $(1992)^{7}$ compararam a resposta tissular em ratos frente ao implante intraperitoneal de três diferentes próteses, utilizadas para o reparo de falha na parede abdominal: Gore-Tex, Mersilene e VicrylMersilene. A menor adesão ao omento e intestino foi observada com o uso da malha de poliéster (Mersilene); a Gore-Tex foi responsável por maior acúmulo de neutrófilos e a Vicryl-Mersilene mostrou maior quantidade de fibrose.

Klosterhalfen et al. (1997) ${ }^{6}$ implantaram malhas de polipropileno e poliéster em ratos para análise morfológica e morfométrica. O grau de inflamação, o padrão de fibrose e a composição da matriz celular exerceram influência decisiva na função da parede abdominal. A fibrose e inflamação foram associadas à densidade, processamento e tipo de superfície do material. Os autores sugerem o desenvolvimento de novas malhas que reduzam a quantidade de material usado e com biocompatibilidade definida, já que as disponíveis restringem a função da parede abdominal.

O uso da malha de poliéster para a reconstrução de defeitos e hérnias abdominais foi estudado por Shoukry et al. $(1997)^{8}$. O material foi implantado de forma retroperitoneal ou intraperitoneal e testado em três espécies animais com defeito experimental e em 14 animais de seis espécies, com hérnias umbilicais e ventrais. A observação post-mortem do grupo com defeito experimental, até seis meses após a cirurgia, não mostrou complicações significativas e a malha foi firmemente incorporada à parede abdominal. Concluíram que a malha de poliéster tem excelente biocompatibilidade e constitui uma alternativa de valor.

Leber et al. (1998) ${ }^{9}$ ao avaliarem a malha de poliéster monofilamentada (Mersilene), Marlex, GoreTex e Prolene no reparo de hérniais incisionais em humanos, verificaram que a malha de poliéster mutltifilamentada teve o maior número de complicações, com maior formação de fístulas, infecção e recorrência.

Como em grandes perdas da parede abdominal faz-se necessário o emprego de material prostético, o trabalho teve por objetivo comparar uma malha comercial de poliéster com o pericárdio bovino preservado em glicerina na reconstituição de defeitos da parede abdominal.

\section{Métodos}

Foram utilizados 30 ratos, Wistar, fêmeas, com peso inicial médio de 180 gramas, fornecidos pelo Biotério Central da Unesp - Campus de Botucatu. Os animais foram divididos, por sorteio, em dois grupos eqüitativos (I e II) e alocados em jaulas individuais, com água e ração ad libitum.

Quinze minutos após a aplicação de $0,05 \mathrm{mg} / \mathrm{kg}$ de atropina por via subcutânea, a anestesia foi efetuada com uma mistura composta de $0,2 \mathrm{ml}$ de água destilada, $0,8 \mathrm{ml}$ de cloridrato de xilazina e $2 \mathrm{ml}$ de cloridrato de ketamina, na dose de $0,2 \mathrm{ml} / 100 \mathrm{~g}$ de peso vivo, por via intramuscular. Em seguida à tricotomia da parede abdominal ventral, os animais foram posicionados em decúbito dorsal e a anti-sepsia efetuada com álcool iodado. Realizou-se uma incisão de pele e tecido subcutâneo pré-retro umbilical na linha média. A pele foi afastada e excisou-se um retângulo de 2,0 x 1,5 cm, incluindo os músculos reto abdominal, oblíquo abdominal externo, oblíquo abdominal interno, transverso abdominal e peritônio. 
Comparação entre pericárdio bovino preservado em glicerina e malha de poliéster no reparo de falhas da parede abdominal em ratos

No Grupo I, a parede abdominal foi reparada com emprego de malha de poliéster, fixada com as bordas dobradas, junto à face externa do defeito, utilizando-se pontos isolados simples. No Grupo II, a reconstituição do defeito foi com fragmento de pericárdio conservado em glicerina, fixado à face externa da borda do defeito com sutura contínua festonada. Em ambos os grupos, o tecido subcutâneo foi aproximado com uma sutura tipo Cushing e a pele em pontos isolados simples. $\mathrm{O}$ fio utilizado foi o náilon n. ${ }^{\circ}$ 6-0.

Cinco animais de cada grupo foram sacrificados com éter aos 15, 60 e 90 dias de pós-operatório. O local cirúrgico foi avaliado macroscopicamente quanto a sinais de infecção, presença ou não de aderências das estruturas abdominais aos implantes, fixação dos mesmos em relação à parede abdominal e mensuração dos defeitos induzidos $\left(\mathrm{cm}^{2}\right)$. O pericárdio e a malha de poliéster foram colhidos em conjunto com os músculos circundantes, fixados em formalina a $10 \%$, incluídos em parafina e processados da maneira habitual. As lâminas foram coradas pela técnica de Hematoxilina-Eosina. A histologia analisou os tecidos quanto à cicatrização e aceitação do material implantado.

Foi utilizada a análise estatística de variância de um delineamento inteiramente ao acaso, com os tratamentos no esquema fatorial formados por dois momentos de avaliação (15 e 90 dias) e dois tipos de implante (malha e pericárdio), com cinco repetições de cada tratamento. O nível de significância adotado foi de 5\% (Zar, 1996) ${ }^{10}$.

\section{Resultados}

Durante os procedimentos cirúrgicos, notou-se maior dificuldade na fixação da malha de poliéster à parede abdominal do que o pericárdio conservado em glicerina, por causa da pouca flexibilidade da mesma. Os animais não manifestaram perda de apetite ou alteração comportamental durante o experimento.

Na avaliação macroscópica de ambos os grupos, os implantes permaneceram fixados à parede abdominal e forneceram suporte às vísceras abdominais. Em todos os momentos, os materiais implantados estavam presentes, porém houve diferença estatisticamente significante com relação ao tamanho dos defeitos cirúrgicos entre os dois grupos (Tabela 1). O Grupo II apresentou tamanho maior quando comparado ao Grupo I; entretanto, em relação ao tempo inicial (15 dias) e final (90 dias), não houve diferença significativa no tamanho da ferida de ambos os grupos.
TABELA 1 - Tamanho dos defeitos cirúrgicos entre os grupos I e II.

\begin{tabular}{lc}
\hline & Tamanho da ferida $\left(\mathrm{cm}^{2}\right)$ \\
\hline GRUPO I (malha) & $3,4 \mathrm{a}(0,35)$ \\
GRUPO II (pericárdio) & $4,0 \mathrm{~b}(0,38)$ \\
\hline * médias de parâmetros seguidos de letras iguais não \\
diferem significativamente $(\mathrm{p}>0,05)$
\end{tabular}

Foi observada deiscência de pontos aos 10 dias de pós-cirúrgico em um rato do grupo I, que foi tratada com curativos tópicos e aplicação de antibiótico. Na época do sacrifício, aos 15 dias de pós-operatório, a malha ainda apresentava-se exposta. Havia aderências do omento e baço à malha, porém sem sinais de infecção na cavidade abdominal. Em todos os períodos de observação verificou-se presença de aderências de estruturas abdominais à malha nos outros animais do grupo I. Com maior freqüência, alças intestinais e omento estavam aderidos à malha, além do fígado e baço em menor número (Figura 1). A comparação entre as aderências de vísceras abdominais aos implantes do Grupo I e Grupo II foram estatisticamente significantes (Tabela 2), já que no Grupo II ocorreu apenas aderência de omento, em 26,7\% dos ratos (Figura 2). Não houve diferença estatística significante entre o período inicial e final do estudo, nos grupos I e II separadamente. Em ambos os grupos, as aderências aparentemente não interferiram com o funcionamento dos órgãos.

TABELA 2 - Número de aderências entre os grupos I e II.

\begin{tabular}{lc}
\hline & Número de aderências \\
\hline GRUPO I (malha) & $1,8 \mathrm{a}(0,29)$ \\
GRUPO II (pericárdio) & $0,5 \mathrm{~b}(0,32)$ \\
\hline
\end{tabular}

*médias de parâmetros seguidos de letras iguais não diferem significativamente $(\mathrm{p}>0,05)$

No exame histológico dos animais do grupo I, observou-se em todos os momentos a presença de um tecido cicatricial com grande proliferação de neovasos, infiltrado de tecido fibroblástico pelas porosidades da malha, bem como ao seu redor, e presença de células gigantes tipo corpo estranho em grande quantidade. As células polimorfonucleares estavam presentes apenas no primeiro momento (15 dias), evidenciando ainda processo inflamatório agudo. No Grupo II, a reação inflamatória periférica ao implante foi menos intensa em todos os momentos, quando comparada ao grupo I. As células gigantes estavam presentes apenas 
no primeiro momento, assim como os fibroblastos. $\mathrm{O}$ pericárdio apareceu sob a forma de uma estrutura amorfa acidofílica. Aos 90 dias de pós-operatório, ne-

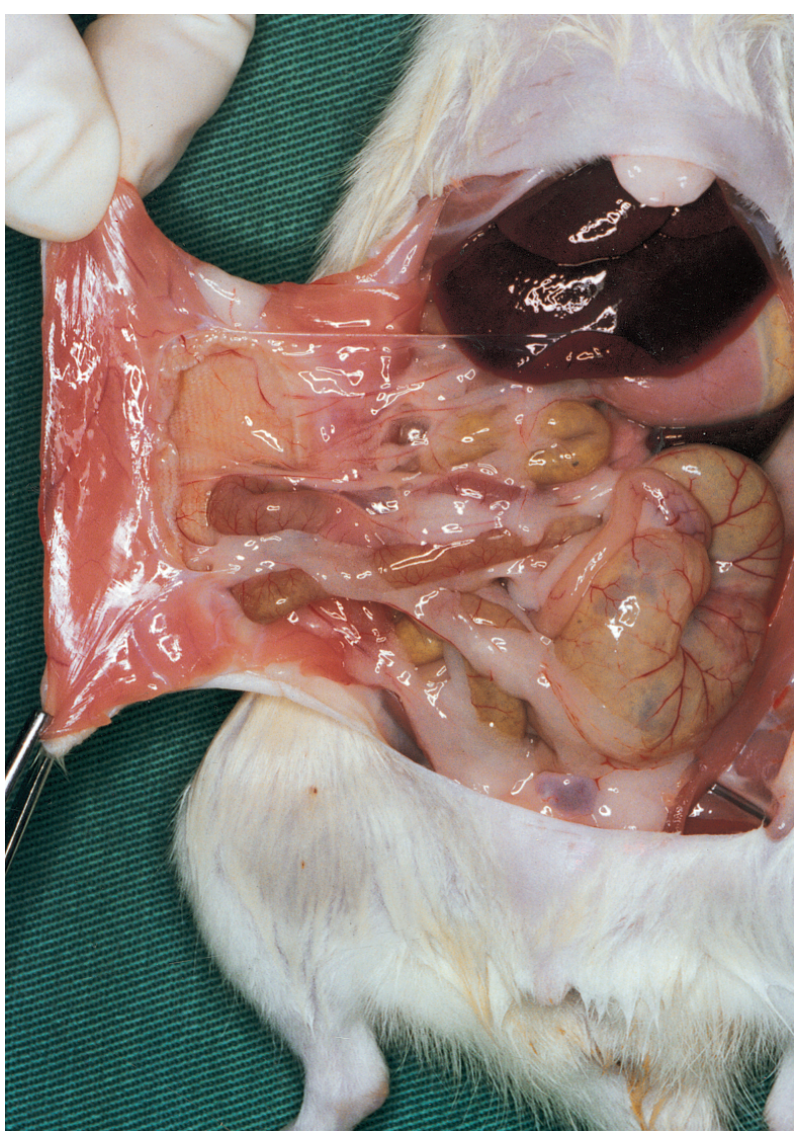

FIGURA 1 - Animal do grupo I aos 90 dias de pós-operatório. Observam-se firmes aderências das vísceras ao implante.

\section{Discussão}

A malha de poliéster apresentou como vantagens a pronta disponibilidade e esterilização. Por outro lado, mostrou ser mais difícil de manusear que o pericárdio. Embora estudos utilizando pericárdio tanto conservado em glicerina ${ }^{4}$ como glutaraldeído ${ }^{1}$ tenham apresentado bons resultados, optou-se pela glicerina em virtude do baixo custo, além da facilidade de aquisição e estocagem $^{4,5}$.

Mesmo sem estudos de tração, aparentemente ambos materiais proporcionaram suporte abdominal, fato comprovado por Santillán-Doherty et al. (1995) ${ }^{1}$ com estudos em cães. Quando utilizada no reparo de hérnias incisionais em humanos, a prótese de poliéster foi considerada suficientemente flexível e elástica para adaptar-se ao saco peritoneal ${ }^{2}$. Shoukry et al $(1997)^{8}$, num estudo experimental, concluiu que a malha possui excelente biocompatibilidade, incorporando-se firmemente à parede abdominal. Entretanto, no presente experimento observou-se menor flexibilidade da parede nhuma célula anteriormente identificada foi verificada na periferia do pericárdio (polimorfonucleares, mononucleares, fibroblastos, neovasos, células gigantes).

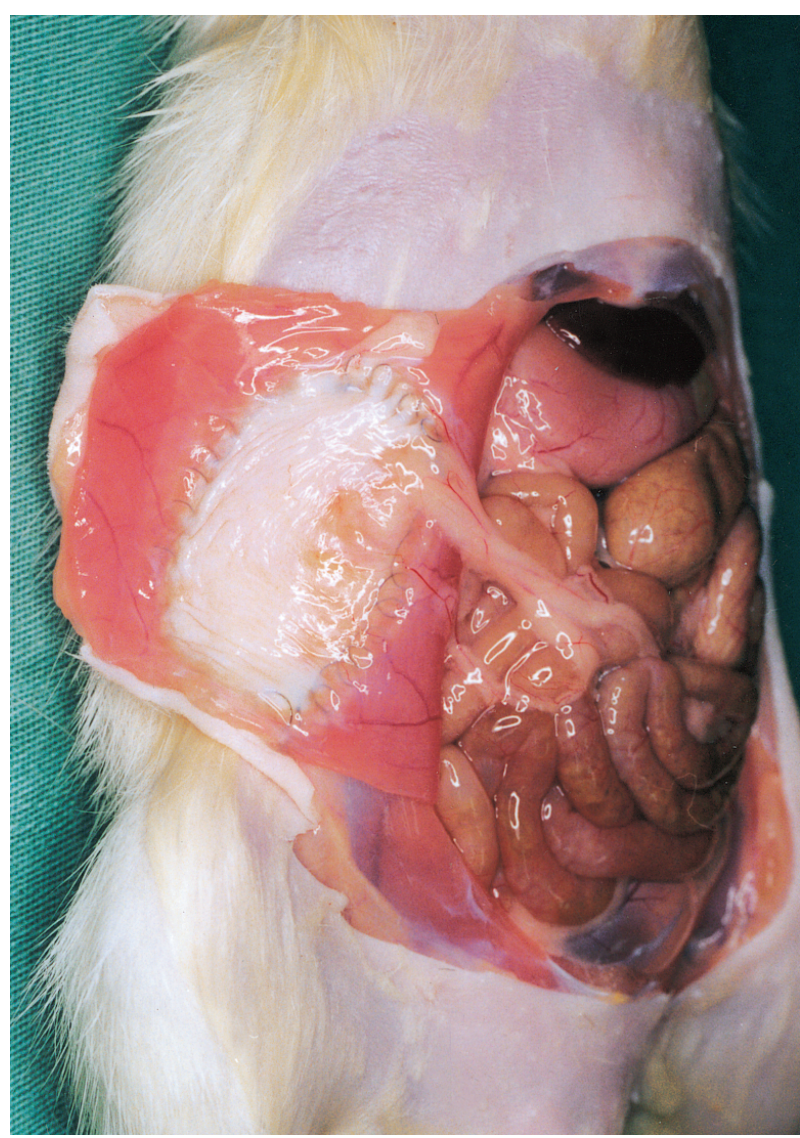

FIGURA 2 - Animal do grupo II aos 90 dias de pós-operatório, com aderência do omento ao pericárdio implantado.

abdominal com o uso da malha de poliéster do que com o pericárdio conservado em glicerina, além de diferença de tamanho dos defeitos cirúrgicos durante o crescimento do animal. Estes fatos se tornam importantes na dependência da extensão do defeito da parede abdominal, bem como no peso das vísceras a serem suportadas, especialmente ao utilizar implantes am animais jovens.

Em contato com as estruturas abdominais, a malha de poliéster proporcionou formação de adesões ao omento e vísceras, maiores e mais intensas do que o pericárdio bovino. Pans e Pierard (1992) ${ }^{7}$ também notaram adesões do intestino e omento ao utilizarem a malha de poliéster em ratos. No entanto, os animais do experimento não manifestaram sinais de comprometimento dos órgãos devido às aderências, diferentemente de Leber et al. (1998) ${ }^{9}$ que, ao empregarem a malha de Mersilene em humanos, verificaram um alto grau de complicações como formação de fístulas, infecção e recorrência. Um fato interessante foi que no animal que apresentou deiscência dos pontos, a malha atuou 
como uma barreira de proteção e evitou o desenvolvimento de peritonite. As aderências devido ao uso de pericárdio conservado em glicerina se limitaram especialmente ao omento, como também verificado por Santillán-Doherty et al. (1995) ${ }^{1}$ ao utilizarem o pericárdio preservado em glutaraldeído.

Histologicamente a reação dos tecidos aos implantes foi mais intensa nos animais do grupo I, com presença de fibroblastos, células tipo corpo estranho e grande quantidade e neovasos. Como citado por Wantz (1991) ${ }^{2}$, ao utilizar a malha de poliéster em hérnias incisionais, a rápida resposta fibroblástica assegura a fixação do implante ao tecido. Entretanto, vale salientar que a fibrose exerce influência na função da parede abdominal, como observado por Klosterhalfen et al. (1997) ${ }^{6}$, ao implantarem malhas de polipropileno e poliéster em ratos. No grupo II, ocorreu baixa reação inflamatória, com presença de poucas células tipo corpo estranho, fato referido por Santillán-Doherty et al. (1995) ${ }^{1}$.

\section{Conclusão}

A malha de poliéster oferece maior resistência estrutural e resposta fibroblástica mais intensa; contudo, promove grande quantidade de aderências às vísceras abdominais, quando comparada ao pericárdio bovino.

\section{Referências}

1. Santillán-Doherty P, Jasso-Victoria R, Sotres-Vega A, Olmos R, Arreola JL, Garcia D, Vanda B, Gaxiola M. Reparación de defectos de pared tóracoabdominal de perros con bioprótesis de pericardio bovino. Rev Invest Clin 1995;47:439-46.

2. Wantz GE. Incisonal hernioplasty with Mersilene. Surg Gynecol Obstet 1991;172:129-37.

3. Baptista ZC, Daleck CR, Shimano AC, Acalesski AMS. Estudo comparativo da resistência à tração do peritônio (bovino, eqüino, suíno, e canino) a fresco e conservado em glicerina. Braz J Vet Res An Sci 1996;33:305-11.

4. Alvarenga J. Possibilidades e limitações da utilização de membranas biológicas preservadas em cirurgia. In: Daleck CR. Tópicos em cirurgia de cães e gatos. Jaboticabal: FUNEPUNESP; 1992. p 33-42.

5. Leite JBF, Marques AF, Gomes OM, Pigossi N. A glicerina e a preservação dos tecidos. Rev Paul Med 1979;93:81-4.

6. Klosterhalfen B, Klinge U, Henze U, Bhardwaj R, Conze J, Schumpelick V. Morphologic correlation of functional abdominal wall mechanics after mesh implantation. Langenbecks Arch Chir 1997;382:87-94.

7. Pans A, Pierard GE. A comparison of intraperitoneal prostheses for the repair of abdominal muscular wall defects in rats. Eur Surg Res 1992;24:54-60.

8. Shoukry M, El-Keiey M, Hamouda M, Gadallah S. Commercial polyester fabric repair of abdominal hernias and defects. Vet Record 1997;140:606-7.

9. Leber GE, Garb JL, Alexander AI, Reed WP. Long-term complications associated with prosthetic repair of incisional hernias. Arch Surg 1998;133:378-82.

10. Zar JK. Bioestatistical analysis. New Jersey: Prentice-Hall; 1996.

$\overline{\text { Quitzan GQ, Rahal SC, Rocha NS, Crocci, AJ. Comparison of glycerin preserved bovine pericardium }}$ and a polyester mesh for the repair of abdominal wall defects in rats. Acta Cir Bras [serial online] 2003 Jul-Aug;18(4). Available from URL: http://www.scielo.br/acb.

ABSTRACT - Purpose: The aim of the study was to compare polyester mesh and glycerin preserved bovine pericardium for the repair of abdominal wall defects. Methods: Thirty rats divided into two equal experimental groups were used. A $2.5 \times 2 \mathrm{~cm}$ rectangular defect including all abdominal muscles and peritoneum was performed. The defect was reconstructed using polyester mesh in group I and glycerin preserved bovine pericardium in group II. The animals were submitted to euthanasia at 15, 60 and 90 days postoperatively, and the surgical area was evaluated by macroscopic and microscopic examination. Results: The animals of the Group I had more abdominal adhesions and those were more severe than the animals of the Group II. The microscopic examination showed incorporation of the tissues in the implants with accentuated fibroblastic reaction in the animals of the group I. Conclusion: The polyester mesh offers more structural resistance and more fibroblastic response; however, leads to greater amount of abdominal viscera adhesions when compared to preserved bovine pericardium.

KEY WORDS - Abdominal wall. Mesh. Polyester. Pericardium. Rats.

Conflito de interesse: nenhum

Correspondência:

Fonte de financiamento: nenhuma

Juliany Gomes Quitzan

Rubião Júnior, s/n

18618-000 Botucatu - SP

Tel: (14)6802-6252 - juquitzan@yahoo.com

Data do recebimento: 12/03/2003

Data da revisão: 21/03/2003

Data da aprovação: 04/04/2003 